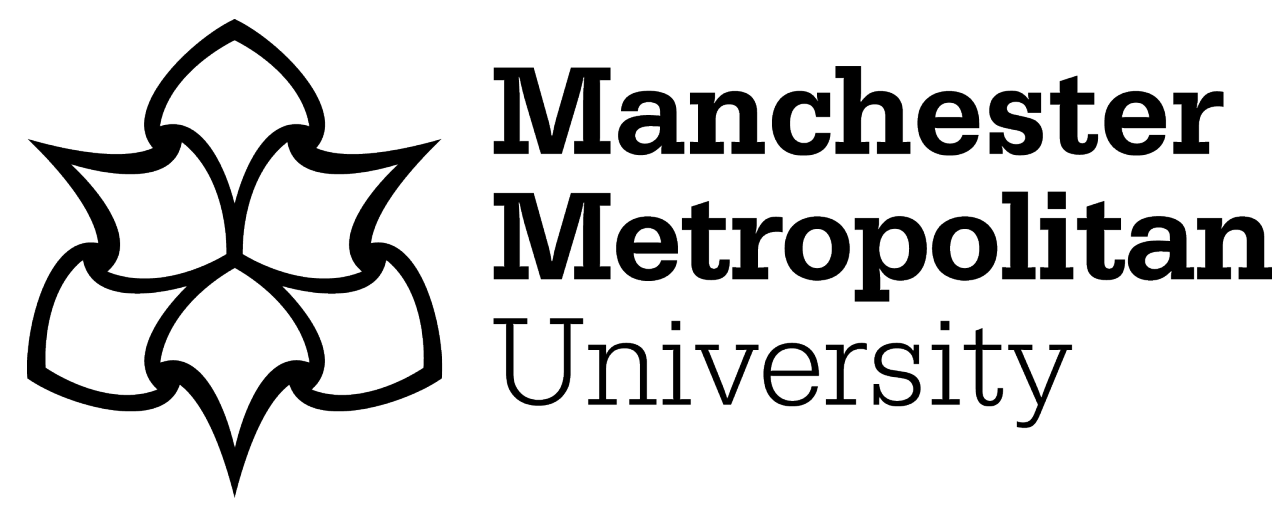

Nyashanu, M, Chireshe, R, Mushawa, F and Ekpenyong, MS (2021) Exploring the challenges of women taking antiretroviral treatment during the COVID-19 pandemic lockdown in peri-urban Harare, Zimbabwe. International Journal of Gynecology and Obstetrics, 154 (2). pp. 220-226. ISSN 0020-6695

Downloaded from: https://e-space.mmu.ac.uk/629278/

Version: Published Version

Publisher: Wiley

DOI: https://doi.org/10.1002/ijgo.13771

Usage rights: Creative Commons: Attribution-Noncommercial 4.0

Please cite the published version 
Gynecology

\title{
Exploring the challenges of women taking antiretroviral treatment during the COVID-19 pandemic lockdown in peri- urban Harare, Zimbabwe
}

\author{
Mathew Nyashanu' ${ }^{1}$ () | Rumbidzai Chireshe ${ }^{2}$ | Fungisai Mushawa ${ }^{1}$ | \\ Mandu S. Ekpenyong ${ }^{3}$
}

${ }^{1}$ Nottingham Trent University, Nottingham, UK

${ }^{2}$ Department of Nursing and Public Health, Kwazulu Natal University, Durban, South Africa

${ }^{3}$ Manchester Metropolitan University Faculty of Health, Manchester, UK

\section{Correspondence}

Mathew Nyashanu, Nottingham Trent University, 50 Shakespeare Street, Nottingham NG1 4FQ, UK.

Email: mathew.nyashanu@ntu.ac.uk

\begin{abstract}
Objective: To explore the challenges of women taking antiretroviral treatment (ART) during the COVID-19 pandemic lockdown in a peri-urban area.

Methods: An exploratory qualitative study approach was used. Semi-structured questions were devised and used to elicit data on the impact of the COVID-19 lockdown on women accessing treatment for HIV. Twenty women were interviewed through contacts from community and faith organizations in peri-urban Harare. All interviews were audio-recorded, transcribed verbatim and entered into NVivo to make analysis easy. The data were thematically analyzed, underpinned by the four phases of data analysis in the Silences Framework.

Results: The study discovered that transport problems, confusing COVID-19 restrictions, abuse by police and soldiers at roadblocks, a shortage of medication, lack of health check-up routines, involuntary default of ART, and a shortage of personal protective equipment affected HIV-positive women accessing ART during the COVID-19 lockdown.

Conclusion: People living with HIV need a robust supporting environment and a functioning health system. In response to COVID-19 all services were halted to prevent the spread of COVID-19. Pandemic preparedness is important in keeping an adequate supply of ART and responding to the needs of individuals on HIV treatment.
\end{abstract}

KEYWORDS

antiretroviral treatment, COVID-19, HIV, pandemic, women

\section{1 | INTRODUCTION}

The COVID-19 epidemic has caused a disastrous situation for all affected populations, particularly vulnerable groups within communities, such as people with chronic diseases, i.e. HIV and AIDS. ${ }^{1}$ These populations need functioning healthcare systems, sanitation and hygiene, safe water, and a healthy food supply. Due to the epidemic, people cannot maintain their jobs, resulting in the deterioration of the economy and public health services. Furthermore, important institutions, such as the health sector, were constantly under pressure

This is an open access article under the terms of the Creative Commons Attribution-NonCommercial License, which permits use, distribution and reproduction in any medium, provided the original work is properly cited and is not used for commercial purposes.

(c) 2021 The Authors. International Journal of Gynecology \& Obstetrics published by John Wiley \& Sons Ltd on behalf of International Federation of Gynecology and Obstetrics 
and were unable to respond adequately to the health demands of the population. ${ }^{2}$ Communities and social networks have fallen apart, and individuals have had difficulties in sustaining their livelihoods and living healthily. In response to the challenges of the COVID-19 outbreak, all countries underwent a lockdown period as a strategy to stop the spread of the infection. ${ }^{3}$ Under lockdown, all services were halted, and people were restricted indoors. Nutrition and access to health services for the wider population became a challenge in many low- and middle-income countries (LMICS) during the COVID-19 pandemic.

$\mathrm{HIV}$ is one of the leading causes of preventable mortal infectious diseases globally. In total, 37.9 million people have tested positive with the virus and two-thirds of them live in sub-Sahara Africa. ${ }^{4}$ Since the rollout of antiretroviral therapy (HAART) in sub-Saharan Africa in the early 2000s, the life expectancy of people living with HIV (PLWH) has increased. ${ }^{5}$ However, the gains made in reducing mortality from HIV-related complications are being threatened by COVID-19 restrictions, implemented to curb the spread of the pandemic.

HIV/AIDS is still a persistent global health problem, particularly in LMICs. ${ }^{6}$ Enormous steps have been undertaken to treat and prevent HIV, such as the "90-90-90 targets" by the Joint United Nations Program on HIV/AIDS, which means that $90 \%$ of PLWH know their status, $90 \%$ of PLWH who know their status are on treatment, and $90 \%$ of PLWH on treatment are virally suppressed by $2020 .^{7}$ However, there is still much to be done to stop the spread of HIV and keep a supply of antiretroviral drugs (ARVs), especially during the current COVID-19 pandemic. Patients with HIV risk running out of life-saving drugs because of quarantines and lockdowns aimed at containing the COVID-19 pandemic. The lockdown makes it difficult to replenish vital medicine stocks for chronic conditions such as HIV. ${ }^{8}$ Most of the patients do not know where to collect their next ARV refill. Lockdowns and restrictions imposed by the government do not clearly explain how patients with HIV are to collect their medication, which means many patients are going to run out of their HIV treatment with a possibility of relapse. ${ }^{9}$

Some patients with HIV fear letting other people know why they are desperate to get out of the cities, because they are afraid to be stigmatized by others. ${ }^{10}$ It is believed that lockdowns in various cities have also meant that people with HIV who had travelled away from their hometowns have not been able to return home and access HIV services, including treatment, from their usual providers. Adherence to antiretroviral treatment (ART) is a key factor in ensuring optimal positive clinical health outcomes and is associated with an improved survival rate among patients with HIV and AIDS. ${ }^{11}$ Sustained high levels of adherence (taking $95 \%$ or more of medication as prescribed) are essential for treatment success. ${ }^{12}$ Suboptimal adherence to treatment has been associated with virologic, immunologic, and clinical failure, and may increase the risk of resistance to first-line ARVs. In light of the above discussion, the aim of the present study was to explore the experiences of women taking ART during lockdown.

\section{MATERIALS AND METHODS}

The present study employed an exploratory qualitative study (EQS) approach. As the name suggests, an EQS is designed to explore the topic under consideration to better understand it rather than offer a final and conclusive solution to existing problems under investigation. ${ }^{13}$ In doing so, an EQS may also identify possible areas for further investigation. As such, EQS is useful in understanding the overview of an existing issue from a new perspective and can provide key information for future interventions. ${ }^{14}$ Semistructured questions were devised and used to elicit experiences on the impact of the COVID-19 lockdown on women accessing treatment for HIV. The interview protocol was informed by the literature on access to sexually transmitted infections and HIV treatment among vulnerable groups from previous primary and secondary research studies. To test the appropriateness of the interview schedule, four women accessing HIV treatment were interviewed. After the completion of the pilot interviews, the women were asked whether they felt that the interview schedule was suitable for the topic in question. None of the four women suggested any substantial changes to the interview schedule and it was therefore adopted for use in the research study. However, where appropriate, their comments were included to shape the final research interview schedule.

The Joint Research Ethics Committee (JREC) from the University of Zimbabwe granted the ethical approval for this study. A total of 20 women were interviewed through contacts from the community and faith organizations in peri-urban Harare. Letters and information sheets were sent to organizations and faith groups for women, inviting their members to take part in the research study. Only those women who agreed to take part in the research study had their names forwarded to the researchers to organize interview dates. The interviews were held at community and faith group centers where the women normally meet for community and faith activities. This was to make sure that the research participants were comfortable and free to answer questions in an environment they were accustomed to. All the research participants signed a consent form that accorded them the right to withdraw from the study without stating any reason. Each interview lasted $1 \mathrm{~h}$.

The inclusion criteria included women who were HIV positive and taking ART. The women were supposed to stay in peri-urban Harare before the lockdown. It was important to recruit a heterogeneous sample with regard to the cut off time they started staying in peri-urban Harare to make sure that their experiences during lockdown were explored under a uniform situation. The interviews were conducted by two researchers who were both women. This was important to enhance openness and the sharing of silence among women as opposed to when a male researcher is involved. All interviews were audio-recorded, transcribed verbatim, and entered into NVivo to make analysis easy. ${ }^{15}$ For the verification of accuracy, all transcriptions were taken back to the research participants for confirmation. This is deemed important as it validates the data collected before analysis. ${ }^{16}$ 
After the organization of the data by NVivo, the analysis of the data started with the coding of the data into broad categories by the two researchers using the four phases of data analysis in the Silences Framework. ${ }^{17}$ During phase 2 of data analysis, the researchers took the categorized broad themes to the research participants for verification and confirmation as a true reflection of what they had said during the interviews. The research participants at this point had the opportunity to refute or confirm the constructed broad themes in line with their contribution at interview. At phase 3 of data analysis, the data from phase 2 were taken to a collective voice group for validation and verification. The collective voice group is a group of people who mirrored the research participants but did not participate in the research study. For example, this group was made up of HIV-positive women receiving treatment and living in peri-urban Harare but who did not take part in the research study. At this point, the user voice group validated and verified the data coined in phase 2 . This was meant to critique the data using an associative eye. Finally, in phase 4 the researchers analyzed the data in line with the contributions made in each phase to form the final output of the research study. Figure 1 shows the four phases of the analysis described above.

The research participants were given an information sheet to read and ask question before participating in the research study.

\section{3 | RESULTS}

After analysis of the data on the impact of the COVID-19 lockdown on HIV-positive women, the seven themes identified included transport problems, confusing COVID-19 restrictions, abuse by police and soldiers at roadblocks, shortage of medication, lack of health check-up routines, involuntary default of ARVs, and a shortage of personal protective equipment (PPE).

\section{1 | Transport problems}

All the research participants agreed that the travelling restrictions made them miss appointments and/or sometimes made it difficult to travel to healthy facilities to collect their supply of ARVs because

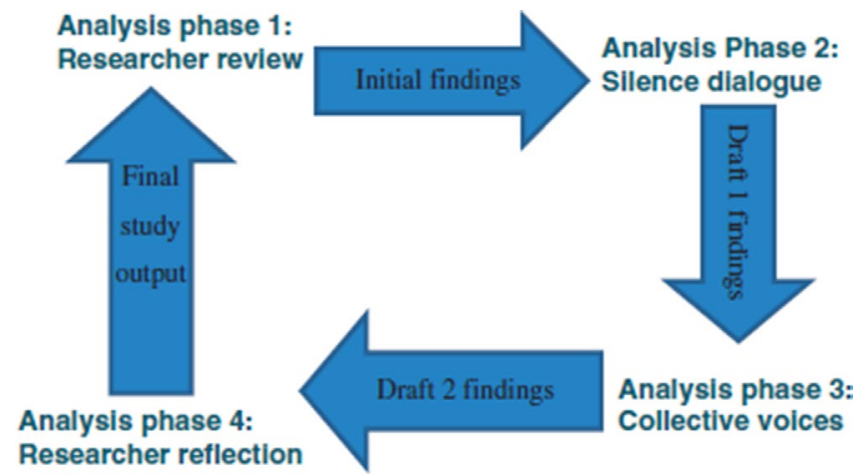

FIGURE 1 The four phases of data analysis in The Silences Framework $^{17}$ public transport was not allowed to move or take people from one place to another.

I live 60 kilometers from the health facility I get my ARVs supply and right now I do not know how I am going to go for my next appointment because of this pandemic... no transport is servicing our area. (a 46-year-old woman)

Even though I live $20 \mathrm{~km}$ away from the clinic, I am not sure I am still fit to walk that long to get to the clinic... especially with this chronic condition that I have had for the past 10 years. (a 50-year-old woman)

\section{2 | Confusing COVID-19 information}

Research participants expressed that they all had a general idea of what COVID-19 was, although there was a lot of wrong information that was going around with no-one to rectify it. They felt that there was no clear or strategic policy dealing with the dissemination of information about the pandemic to the people.

Most of the information we heard was through social media and some of the information is not as clear as one would want it to be, I have a lot of questions which are unanswered. (a 29-year-old woman)

This is the most difficult time to survive. We are afraid of so much information, scary information... We need clear communication from those in authority in future to avoid this unnecessary fear. (a 36-year-old woman)

\subsection{Abuse by police and soldiers at roadblocks}

Encounters with the authorities, in most cases, in Zimbabwe is not a pleasant experience, especially the police and soldiers at roadblocks. With the introduction of these travelling restrictions, roadblocks were established to help enforce these restrictions.

Police are the most unreasonable people I have ever met; they act like they will never fall sick, or they do not have relatives who are on this ARV program... imagine I had to spend more than $2 \mathrm{~h}$ pleading with them to pass. (a 48-year-old man)

Everyone knows that the police are very unreasonable. They asked to see my hospital cards, violating my confidentiality in the process. I was not happy at all. (a 36-year-old woman) 


\subsection{Shortage of medication}

Some of the research participants acknowledged that some of the clinics ran short of ARVs due to people being given supplies for 3-6 months. They reported that those who had got to the clinics first got enough supplies for 3-6 months.

By the time that I made it to my local clinic where I normally collect my ARVs, the nurse told me that I was late, and I could only get supply for 1 month and I am now wondering where I will get my next supply. (a 42-year-old woman)

I could only get a supply for 2 months because the clinic had been giving out 3-6 months' supply on the first come first serve basis... I am thinking of going to big hospitals to get more supply. (a 28-year-old woman)

\subsection{Lack of health check-up routines}

The research participants reported that there were no regular checks, i.e. blood pressure, temperature, blood glucose, and general check-ups. They also found it challenging to communicate with the nurse through a window just to drop their medical cards and sit as far as possible waiting to collect their medication. Although this was part of enforcing social distancing for individuals, they found it difficult to understand and acknowledge.

It is exceedingly difficult to be treated like someone with leprosy but anyways I do understand the fear this disease has instilled in us. It is difficult to understand still... more of a concern, I could not get any regular check-ups which I normally get as a person living with a chronic condition. (a 33-year-old woman)

Remember we have HIV, and our health depends on regular checks and some of us have developed other conditions like BP and with no checks we do not know how we are doing right now. (a 43-year-old woman)

\section{6 | Involuntary default}

Most of the research participants reported involuntary default of medication due to their medication running out while being locked down in a different location far from their homes. The research participants also reported difficulties in getting supplies at health facilities where they were not registered.
I spend 2 weeks without taking medication as I was locked down in Bubi, where I had visited my sister. The local clinic told me that they had supplies for their registered patients only and advised me to go to my registered clinic which was impossible due to lockdown. (a 49-year-old woman)

I had visited my brother in Bocha when the lockdown happened. I could not make my way back to Gweru until after 3 weeks... The local clinic could not give me any supplies, so I had to default for 1 week until I returned to my Gweru. (a 37-year-old woman)

\section{7 | Shortage of PPE}

The research participants reported difficulties in acquiring PPE for themselves as it was very expensive and sometimes out of stock. They reported the improvisation of PPE to protect themselves but sometimes the improvisation was not fit for purpose.

With fear of infection, everyone wanted to get PPE, but it was very expensive. I ended up covering my mouth using an old cloth and I don't know whether it works or not... Honestly, we needed help with PPE as vulnerable people. (a 49-year-old woman)

I went round all shops and I could not get any PPE to cover myself... I ended up moving around with nothing on my mouth... You don't even know when you will be infected. (a 42-year-old woman)

\section{4 | DISCUSSION}

Transport problems affect many health systems in LMICs owing to poor infrastructure. ${ }^{18,19}$ During COVID-19, the Zimbabwean government effected restrictions on unnecessary travel including public transport. ${ }^{20}$ Many research participants reported difficulties in travelling to local clinics to collect ARVs because of the COVID-19 lockdown. They also missed some clinical appointments pertinent for their HIV treatment. In future pandemics, there is the need for the government to make provision for people living with chronic diseases to be ferried to different health facilities to collect their ARVs and attend pertinent clinical appointments during the lockdown periods.

It is important that when there is a pandemic such as COVID-19, the affected communities need to be educated about it. ${ }^{21}$ In doing so, it enables effective control of the pandemic through changes in behavior informed by the information provided. Most of the research participants reported ever-changing information 
about COVID-19, leaving them in fear. It is important that during a pandemic the government establishes effective channels of communication that are available to and understood by all the population. ${ }^{22}$ It is also important that information is managed and disseminated by qualified health practitioners. More importantly, information needs to be simplified to make sure that it is free of technical jargon and easily understood by the lay members of the communities. ${ }^{23,24}$ This is more important when dealing with people accessing ART to ensure that their uptake of medication is not interrupted.

Meanwhile, although it is important that a lockdown should be enforced by law enforcement agents such as police and soldiers, it is essential that the enforcement does not infringe on the rights of citizens, especially those who are vulnerable and accessing medication for chronic conditions such as HIV. ${ }^{25}$ Most of the research participants reported abuse by police and soldiers at roadblocks while on their way to collect their ART. They also reported breaches of their right to confidentiality when the police and soldiers demanded to see their hospital cards. It is important that during pandemic periods police and soldiers are educated about their role during the pandemic, clearly articulating their roles and boundaries to avoid misuses of power, which can impact negatively on vulnerable people accessing ART. There is the need for all law enforcement agents to have a clear knowledge and understanding on the laws governing confidentiality and sharing of information to protect vulnerable individuals accessing ART from being abused. ${ }^{26}$ This is crucial in protecting the rights of patients while upholding their dignity when accessing medication for chronic conditions.

Shortage of medication in LMICs is one of the long-standing health problems affecting many countries in this economic group. ${ }^{27}$ This is normally caused by weak health systems and infrastructure. Most of the research participants reported a shortage of ART during the lockdown period owing to some patients being given treatment supplies for 3-6 months. There is a need for the government to have reserve ART in case of any future pandemics. This will prevent individual patients from taking medication errands during the lockdown period and possibly exposing themselves to infections. There is a need to measure an affordable amount of medication that each patient can get before exhausting the supply in reserve. ${ }^{28}$ For example, instead of giving a supply of medication for up to 5 months, all patients can be given medication equivalent to 3 months to avoid a shortage. This would ensure that every patient receives medication for the first 3 months and gives health facilities time to prepare the supply for the next 3 months.

Regular check-ups for people taking HIV treatment are important to prevent co-morbidities and other complications. ${ }^{29}$ The participants also reported that it was challenging to communicate with the nurse through a window just to drop off their medical cards and sit as far as possible waiting to collect their medication. There is a need to maintain the regular care of individuals on HIV treatment. Health professionals need to be provided with PPE to make sure that they carry out regular checks for vulnerable patients such as those on HIV treatment. This would enable medication to be regularly monitored and replenished. There is also a need for health facilities to explain the changes in patient care to the patients in a more empathetic way to maintain a therapeutic relationship with them and avoid despondence.

Default of medication, whether voluntary or involuntary, has a direct impact on the health and well-being of the patient. ${ }^{30}$ Most of the research participants reported an involuntary default of medication due to their medication running out while being locked down in a different location far from their homes. The research participants reported difficulties in getting supplies at health facilities where they were not registered, and this led to an involuntary default of their ART. With the advent of the COVID-19 pandemic, they were now at risk of interrupting their HIV treatment. ${ }^{31}$ There is a need for the central government to make it easy for individuals accessing ART to access their medication from any health facility in the country rather than referring them to where they are registered. This will circumvent the problem of defaulting on treatment and enhance positive outcomes for individuals on HIV treatment.

Personal protective equipment is one of the most important requirements when fighting an infectious pandemic such as COVID-19. ${ }^{32}$ The shortage of PPE posed a threat of COVID-19 infection to individuals receiving HIV care or on ART. Nearly all the research participants in the present study reported a severe shortage of PPE. The research participants reported difficulties in acquiring PPE for themselves as it was expensive and sometimes out of stock. They reported improvising PPE to protect themselves as they travelled to get their supply of HIV medication. The shortage of PPE also affected the health workers in many healthcare settings, exposing them to possible infection of COVID-19. The shortage of PPE undoubtedly created fear and anxiety among the participants. This was also compounded by the fact that COVID-19 is untreatable. ${ }^{33}$ There is a need for the central government to have a clear policy on the procurement of PPE. This will ensure an adequate stock of PPE and access by vulnerable groups such as people on ART. More importantly, a subsidy on the price of PPE is needed to make it affordable, especially to women accessing ART who are usually unemployed. ${ }^{34}$ This will ensure affordability of PPE in times of pandemics such as COVID-19.

\subsection{Implication for professionals working with PLWH}

There is a need for professionals working with PLWHs to raise awareness among government departments to enlighten other professionals such as the police and soldiers to understand the importance of treating HIV-positive individuals with dignity. Furthermore, professionals working in sexual health and HIV need to carry out a more robust situational analysis to improve pandemic preparedness when delivering services.

\subsection{Limitations of the study}

The present study was carried out in a peri-urban area in Harare. Research encompassing more regions may be necessary to 
understand the generic impact of the COVID-19 lockdown on individuals accessing ART. The study utilized a qualitative paradigm. Another study utilizing mixed methods may be necessary to enable the exploration of issues affecting HIV-positive women from different epistemological and ontological positions.

\section{5 | CONCLUSION}

Pandemic preparedness is important for keeping an adequate supply of ART available to people accessing it. More importantly, robust policies supporting HIV education and awareness are needed to make sure that the public are aware of the need to support individuals affected by HIV.

\section{ACKNOWLEDGMENTS}

Our sincere thanks go to all professionals in the city of Harare who participated in this research study.

\section{CONFLICTS OF INTEREST}

The authors have no conflicts of interest.

\section{AUTHOR CONTRIBUTIONS}

$M N$ : substantial contributions to the conception and design of the work. RC: drafting the work and revising it critically for important intellectual content. FM: final approval of the version to be published. MSE: agreed to be accountable for all aspects of the work in ensuring that questions related to the accuracy are appropriately investigated and resolved.

\section{ORCID}

Mathew Nyashanu (D) https://orcid.org/0000-0001-7324-3837

\section{REFERENCES}

1. San Lau L, Samari G, Moresky RT, et al. COVID-19 in humanitarian settings and lessons learned from past epidemics. Nat Med. 2020;26(5):647-648.

2. Radbruch L, Knaul FM, de Lima L, de Joncheere C, Bhadelia A. The key role of palliative care in response to the COVID-19 tsunami of suffering. Lancet. 2020;395(10235):1467-1469.

3. Meng L, Hua F, Bian Z. Coronavirus disease 2019 (COVID-19): emerging and future challenges for dental and oral medicine. J Dent Res. 2020;99(5):481-487.

4. United Nation Programme on HIV/AIDS. Core epidemiology slides; July (2019). UNAIDS. Global HIV \& AIDS statistics-2019 fact sheet; July 2019; UNAIDS. UNAIDS data 2019, July 2019.

5. Legemate EM, Hontelez JA, Looman CW, de Vlas SJ. Behavioural disinhibition in the general population during the antiretroviral therapy roll-out in Sub-Saharan Africa: systematic review and meta-analysis. Tropical Med Int Health. 2017;22(7):797-806.

6. Bradley EH, Curry LA, Taylor LA, et al. A model for scale up of family health innovations in low-income and middle-income settings: a mixed methods study. BMJ open. 2012;2(4):e000987.

7. Habiyambere V, Ford N, Low-Beer D, et al. Availability and use of HIV monitoring and early infant diagnosis technologies in WHO member states in 2011-2013: analysis of annual surveys at the facility level. PLoS Med. 2016;13(8):e1002088.
8. World Health Organisation. WHO: access to HIV medicines severely impacted by Covid-19 as AIDS response stalls? 2020. https://www.who.int/news/item/06-07-2020-who-access-to-hivmedicines-severely-impacted-by-covid-19-as-aids-response-stalls. Accessed February 21, 2021.

9. Ko NY, Liu HY, Lee HC, et al. One-year follow-up of relapse to risky behaviors and incidence of syphilis among patients enrolled in the HIV case management program. AIDS Behav. 2011;15(5):1067-1074.

10. United Nation Programme on HIV/AIDS. UNAIDS and China working together during Covid-19 outbreak to ensure that people living with HIV continue to get treatment. 2020. https://www.unaids. org/en/resources/presscentre/pressreleaseandstatementarchiv e/2020/february/20200218_china_covid19. Accessed February 21, 2021.

11. Hansana $\vee$, Sanchaisuriya $P$, Durham J, et al. Adherence to antiretroviral therapy (ART) among people living with HIV (PLHIV): a cross-sectional survey to measure in Lao PDR. BMC Public Health. 2013;13(1):1-11.

12. Fraser HS, Jazayeri $D$, Nevil $P$, et al. An information system and medical record to support HIV treatment in rural Haiti. BMJ. 2004;329(7475):1142-1146.

13. Gorynia M, Nowak J, Howak J, Wolniak R. Motives and modes of FDI in Poland: An exploratory qualitative study. J East Eur Manag Stud. 2007;12(2):132-151.

14. Lockett D, Willis A, Edwards N. Through seniors' eyes: an exploratory qualitative study to identify environmental barriers to and facilitators of walking. Can J Nurs Res Arch. 2005;37(3):48-65.

15. Zamawe FC. The implication of using NVivo software in qualitative data analysis: Evidence-based reflections. Malawi Med J. 2015;27(1):13-15.

16. Pyett PM. Validation of qualitative research in the "real world". Qual Health Res. 2003;13(8):1170-1179.

17. Serrant-Green L. The sound of 'silence': a framework for researching sensitive issues or marginalised perspectives in health. J Res Nurs. 2011;16(4):347-360.

18. Finlayson $\mathrm{K}$, Downe $\mathrm{S}$. Why do women not use antenatal services in low-and middle-income countries? A meta-synthesis of qualitative studies. PLoS Med. 2013;10(1):e1001373.

19. Ekpenyong MS, Bond C, Matheson D. Challenges of maternal and prenatal Care in Nigeria. J Intensive Crit Care. 2019;5(1). https://doi. org/10.21767/2471-8505.100125.

20. Makurumidze R. Coronavirus-19 Disease (COVID-19): a case series of early suspects reported and the implications towards the response to the pandemic in Zimbabwe. J Microbiol Immunol Infect. 2020. https://doi.org/10.1016/j.jmii.2020.04.002.

21. Jackson D, Bradbury-Jones C, Baptiste D, et al. Life in the pandemic: Some reflections on nursing in the context of COVID-19. J Clin Nurs. 2020;29(13-14):2041-2043.

22. Allcott H, Boxell L, Conway J, Gentzkow M, Thaler M, Yang DY. Polarization and public health: Partisan differences in social distancing during the Coronavirus pandemic. 2020. NBER Working Paper (w26946).

23. Doody CM, Doody O. Health promotion for people with intellectual disability and obesity. Br J Nurs. 2012;21(8):460-465.

24. Granados A, Jonsson E, Banta HD, et al. EUR-ASSESS project subgroup report on dissemination and impact. Int J Technol Assess Health Care. 1997;13(2):220-286.

25. Jürgens R, Csete J, Amon JJ, Baral S, Beyrer C. People who use drugs, HIV, and human rights. Lancet. 2010;376(9739):475-485.

26. Strode A, Grant K. Children and HIV: using an evidence-based approach to identifying legal strategies that protect and promote the right of children infected and affected by HIV and AIDS. In Working paper prepared for the third meeting of the technical advisory group of the global commission on HIV and the law.

27. Kok MC, Dieleman M, Taegtmeyer M, et al. Which intervention design factors influence performance of community health workers 
in low-and middle-income countries? A systematic review. Health Policy Plan. 2015;30(9):1207-1227.

28. Banteyerga H. Ethiopia's health extension program: improving health through community involvement. MEDICC Rev. 2011;13(3):46-49.

29. Mauser-Bunschoten EP, Fransen Van De Putte DE, Schutgens REG. Co-morbidity in the ageing haemophilia patient: the down side of increased life expectancy. Haemophilia. 2009;15(4):853-863.

30. Zhang NJ, Terry A, McHorney CA. Impact of health literacy on medication adherence: a systematic review and meta-analysis. Ann Pharmacother. 2014;48(6):741-751.

31. American Society of Health-System Pharmacists. Drug shortages roundtable: Minimizing the impact on patient care. Am J Health-Syst Pharm 2018;75(11):816-820.

32. Pallister-Wilkins P. Personal protective equipment in the humanitarian governance of Ebola: between individual patient care and global biosecurity. Third World Q. 2016;37(3):507-523.
33. Albzeirat MK, Al-Tarawneh MS, Khalid N, Zulkepli NN, Islam DMZ. COVID-19 story: the unknown killer and future studies. Int $J$ Multidiscip Sci Adv Technol Special Issue Covid-19. 2020;1(1):1-18.

34. Gilbert M, Dewatripont M, Muraille E, Platteau JP, Goldman M. Preparing for a responsible lockdown exit strategy. Nat Med. 2020;26(5):643-644.

How to cite this article: Nyashanu M, Chireshe R, Mushawa F, Ekpenyong MS. Exploring the challenges of women taking antiretroviral treatment during the COVID-19 pandemic lockdown in peri-urban Harare, Zimbabwe. Int J Gynecol Obstet. 2021;154:220-226. https://doi.org/10.1002/ijgo.13771 